\title{
Desempenho e hematologia de tilápias-do-nilo alimentadas com Saccharomyces cerevisiae e vacinadas contra Streptococcus agalactiae
}

\author{
Rogério Salvador(1), Gustavo da Silva Claudiano(2), Bruna Agy Loureiro(3), Paulo Fernandes Marcusso(2), \\ Silas Fernandes Eto ${ }^{(2)}$, Fabiana Pilarski( ${ }^{(3)}$, Caroline Silva Toazza ${ }^{(1)}$, Julieta Rodini Engrácia de Moraes ${ }^{(2)}$ \\ e Flávio Ruas de Moraes $^{(2)}$
}

\begin{abstract}
(1) Universidade Estadual do Norte do Paraná, Campus Luiz Meneghel, Rodovia BR-369, Km 54, Caixa Postal 261, CEP 86360-000 Bandeirantes, PR. E-mail: salvador@uenp.edu.br, carolstoazza@yahoo.com.br (2)Universidade Estadual Paulista (Unesp), Departamento de Patologia Veterinária, Via de Acesso Prof. Paulo Donato Castellane, s/no, CEP 14884-900 Jaboticabal, SP. E-mail: claudianovet@yahoo.com.br, paulomarcusso@gmail.com, silaseto@hotmail.com, julietaengracia@gmail.com, fruasmoraes@gmail.com ${ }^{(3)}$ Unesp, Departamento de Zootecnia. E-mail: brunaagy@yahoo.com.br, fapilarski@hotmail.com
\end{abstract}

Resumo - O objetivo deste trabalho foi avaliar a inter-relação entre a suplementação alimentar com parede celular de Saccharomyces cerevisae e a vacinação contra Streptococcus agalactiae e seu efeito sobre o desempenho produtivo e as variáveis hematológicas de tilápia-do-nilo (Oreochromis niloticus). Oitenta e quatro tilápias-do-nilo foram distribuídas em 12 caixas de fibra $(n=7)$, em arranjo fatorial $2 \times 2 \times 3$, correspondente a dois níveis de suplementação com parede celular de levedura, dois tipos de inoculação e três tempos de avaliação. Os peixes foram alimentados durante 77 dias. A vacinação dos peixes foi realizada 60 dias após o início da alimentação. Quinze dias após a vacinação, todos os peixes foram submetidos ao desafio com cepa viva de $S$. agalactiae, e 6, 24 e 48 horas após o desafio, o sangue foi colhido da veia caudal para avaliações. Peixes alimentados com ração suplementada apresentam maior ganho de peso e taxa de crescimento específico, e a interação entre os efeitos da dieta e da vacinação resulta em maiores taxas de hematócrito, hemoglobina e leucócitos.

Termos para indexação: Oreochromis niloticus, inflamação, probiótico, sangue, teleósteos, vacinação.

\section{Performance and hematological profile of Nile tilapia fed with Saccharomyces cerevisiae and vaccinated against Streptococcus agalactiae}

\begin{abstract}
The objective of this work was to evaluate the inter-relationship between dietary supplementation with Saccharomyces cerevisiae cell wall and vaccination against Streptococcus agalactiae, and its effect on the productive performance and hematological variables of Nile tilapia (Oreochromis niloticus). Eighty-four Nile tilapia were distributed in 12 fiber boxes $(n=7)$, in a $2 \times 2 \times 3$ factorial arrangement, corresponding to two levels of supplementation with yeast cell wall, two types of inoculation, and three evaluation times. Fish were fed during 77 days. Vaccination of fish was done 60 days after feeding started. Fifteen days after vaccination, all fish were subjected to challenge with live strain of $S$. agalactiae, and 6, 24, and 48 hours after the challenge, blood was collected from the caudal vein for evaluations. Fish fed with supplemented diets show greater weight gain and specific growth rate, and the interaction between the diet and vaccination effects results in higher hematocrit, hemoglobin, and leukocyte rates.
\end{abstract}

Index terms: Oreochromis niloticus, inflammation, probiotics, blood, teleosts, vaccination.

\section{Introdução}

A septicemia por Streptococcus sp. é uma das principais causas de enfermidade na criação de tilápia-do-nilo em cativeiro (Evans et al., 2002). Essa bactéria é isolada em diversos estados e sistemas de criação do Brasil (Salvador et al., 2005). No entanto, o controle de infecções com antibióticos é pouco eficiente e favorece a seleção de microrganismos resistentes (Levy \& Marshall, 2004). Como alternativa, foi proposto o uso de alimentos funcionais e vacinas (Belo et al., 2005, 2012; Moraes \& Moraes, 2009).

O uso integral de Saccharomyces cerevisiae e seus derivados - levedura autolisada ou parede celular em dietas favorece ganho de peso, consumo de ração e taxa de crescimento específico, com melhorias na 
resposta imune inespecífica de diversas espécies de peixes (Rodriguez et al., 2003; Reque et al., 2010).

Há relatos da variação do perfil leucocitário e trombocitário de tilápias-do-nilo que receberam suplementação com levedura autolisada ou parede celular e foram submetidas ao estímulo inflamatório com Aeromonas hydrophila inativada, o que sugere o recrutamento de leucócitos e trombócitos do compartimento sanguíneo para o foco inflamatório (Reque et al., 2010).

Tilápias-do-nilo vacinadas contra $S$. agalactiae apresentaram $15 \%$ de mortalidade contra $70 \%$ do grupo controle após 14 dias, o que mostra a eficiência da vacina (Evans et al., 2004). A suplementação alimentar com parede celular de $S$. cerevisae favoreceu a resposta imune celular em tilápias-do-nilo vacinadas contra S. agalactiae (Salvador et al., 2012).

O objetivo deste trabalho foi avaliar a inter-relação entre a suplementação alimentar com parede celular de S. cerevisae e a vacinação contra $S$. agalactiae sobre o desempenho produtivo e as variáveis hematológicas de tilápia-do-nilo.

\section{Material e Métodos}

O experimento foi conduzido no Laboratório de Patologia de Organismos Aquáticos, do Centro de Aquicultura, da Universidade Estadual Paulista (Unesp), Jaboticabal, SP, de janeiro a março de 2007. Oitenta e quatro tilápias-do-nilo $(125,0 \pm 1,5 \mathrm{~g})$ foram distribuídas em 12 caixas de fibra de $310 \mathrm{~L}$ ( $\mathrm{n}=7$ ), abastecidas com água de poço artesiano, vazão de $1 \mathrm{~L} \mathrm{~min}^{-1}$, com aeração contínua em sistema de recirculação mantido isolado durante o experimento. A qualidade da água permaneceu na faixa adequada ao conforto dos peixes: oxigênio dissolvido na água em $5,5 \pm 0,82 \mathrm{mg} \mathrm{L}^{-1}$, temperatura da água em $28,0 \pm 1,7^{\circ} \mathrm{C} \mathrm{e}$ pH da água de 7,3 $\pm 0,3$ (Boyd, 1990; Sipaúba-Tavares \& Moreno, 1994).

Utilizou-se o delineamento inteiramente casualizado, em arranjo fatorial $2 \times 2 \times 3$, correspondente a dois níveis de suplementação com parede celular de levedura (0 e $0,3 \%$ de parede celular), dois tipos de estímulo (vacina oleosa contra $S$. agalactiae e solução oleosa controle com $0,5 \mathrm{~mL}$ de adjuvante incompleto de Freund) e três tempos de avaliação após desafio com $S$. agalactiae (6, 24 e 48 horas). Foram formados quatro grupos (G), que receberam: ração padrão não suplementada (ração controle) e vacinação (G1); ração controle e $0,5 \mathrm{~mL}$ de adjuvante incompleto de Freund (G2); ração controle suplementada com $0,3 \%$ de parede celular de levedura e $0,5 \mathrm{~mL}$ de adjuvante incompleto de Freund (G3); e ração controle suplementada com $0,3 \%$ de parede celular e vacinação (G4). Em cada grupo, foram feitas três repetições, e cada repetição foi avaliada nos tempos de 6, 24 e 48 horas pós-desafio (HPD).

As rações foram formuladas para serem isoproteicas (28\% de proteína digestível), isoenergéticas (3.240 kcal kg-1 de energia digestível), isofosfóricas ( $0,6 \%$ de $\mathrm{P}$ disponível) e com o mesmo nível de fibra bruta (5\%) (Baccarin \& Pezzato, 2001) (Tabela 1). Os ingredientes foram moídos e homogeneizados em misturador automático. Essa mistura foi submetida ao processo de peletização. As dietas foram secas em

Tabela 1. Composição percentual e químico-bromatológica das dietas experimentais utilizadas para alimentação de tilápia-do-nilo (Oreochromis niloticus).

\begin{tabular}{|c|c|}
\hline Ingredientes & Composição (\%) \\
\hline Farelo de soja & 45,00 \\
\hline Glúten de milho & 9,50 \\
\hline Farinha de peixe & 5,50 \\
\hline Fubá de milho & 15,00 \\
\hline Farelo de trigo & 8,00 \\
\hline Quirera de arroz & 7,60 \\
\hline Alginato & 0,30 \\
\hline Celulose & 1,85 \\
\hline DL metionina & 0,45 \\
\hline Treonina & 0,40 \\
\hline Óleo de soja & 0,50 \\
\hline Fosfato bicálcico & 3,00 \\
\hline Calcário & 2,00 \\
\hline Vitamina $C^{(1)}$ & 0,08 \\
\hline Sal comum & 0,10 \\
\hline Suplemento vitamínico e mineral ${ }^{(2)}$ & 0,40 \\
\hline $\mathrm{BHT}^{(3)}$ & 0,02 \\
\hline Levedura autolisada $^{(4)}$ & 0,30 \\
\hline Energia digestível $\left(\mathrm{kcal} \mathrm{kg}^{-1}\right)$ & $3.240,00$ \\
\hline Proteína digestível (\%) & 28,00 \\
\hline Fibra bruta $(\%)$ & 5,00 \\
\hline Extrato etéreo $(\%)$ & 3,00 \\
\hline$\underline{\text { Relação Ca:P }}$ & 2,95 \\
\hline \multicolumn{2}{|c|}{$\begin{array}{l}\text { (1)Vitamina C, } 35 \% \text { ativa. }{ }^{(2)} \text { Suplemento vitamínico e mineral (Supremais } \\
\text { Produtos Bioquímicos Ltda., Valinhos, SP) por kg de ração: vitamina A, } \\
1.200 .000 \mathrm{UI} \text {; vitamina D3, } 200.000 \mathrm{UI} \text {; vitamina E, } 12.000 \mathrm{mg} \text {; vitamina } \\
\mathrm{K} 3,2.400 \mathrm{mg} \text {; vitamina B1, } 4.800 \mathrm{mg} \text {; vitamina B2, } 4.800 \mathrm{mg} \text {; vitamina } \\
\text { B6, } 48.000 \mathrm{mg} \text {; vitamina B12, } 4.800 \mathrm{mg} \text {; ácido fólico, } 1.200 \mathrm{mg} \text {; ácido } \\
\text { pantotênico, } 12.000 \mathrm{mg} \text {; vitamina C, } 56 \mathrm{mg} \text {; biotina, } 48 \mathrm{mg} \text {; colina, } 65 \mathrm{mg} \text {; } \\
\text { niacina, } 24.000 \mathrm{mg} \text {; Fe, } 10.000 \mathrm{mg} \text {; Cu, } 600 \mathrm{mg} \text {; Mn, } 4.000 \mathrm{mg} \text {; Zn, } 6.000 \\
\text { mg; I, } 20 \mathrm{mg} \text {; Co, } 2 \mathrm{mg} \text {; e Se, } 20 \mathrm{mg} \text {. }{ }^{(3)} \mathrm{Antioxidante}(\beta \text {-hidroxi-tolueno). } \\
\text { (4)Ausente na ração controle, na qual ocorreu a inclusão de } 0,3 \% \text { de caulim } \\
\text { em substituição à levedura autolisada. }\end{array}$} \\
\hline
\end{tabular}

Pesq. agropec. bras., Brasília, v.48, n.8, p.892-898, ago. 2013 DOI: $10.1590 / \mathrm{S} 0100-204 \mathrm{X} 2013000800012$ 
estufa de circulação forçada de ar, a $55^{\circ} \mathrm{C}$, durante 24 horas. Os péletes foram fracionados em diâmetros compatíveis com o tamanho da boca dos peixes e armazenados a $-20^{\circ} \mathrm{C}$. Diariamente, as rações eram descongeladas e oferecidas aos peixes três vezes ao dia (às 9 , às 14 e às $18 \mathrm{~h}$ ), com fornecimento da quantidade equivalente a $3 \%$ da biomassa por dia, durante 77 dias.

Antes do início do experimento, foram avaliadas 30 tilápias-do-nilo $(120 \pm 0,5 \mathrm{~g})$ para padronização do inóculo e da concentração bacteriana letal $\left(\mathrm{CL}_{50}\right)$ utilizada no desafio. Para tanto, amostras de S. agalactiae foram isoladas de tilápias-do-nilo infectadas naturalmente, com sinais de meningoencefalite, e posteriormente identificadas (Salvador et al., 2005). Foram utilizadas três caixas de fibra $(\mathrm{n}=10)$, em delineamento inteiramente casualizado, e cada peixe correspondeu a uma unidade experimental. Os peixes foram inoculados com as concentrações $10^{4}$, $10^{6}$ e $10^{8} \mathrm{UFC} \mathrm{mL}^{-1}$ de $S$. agalactiae, respectivamente. Após 15 dias, os resultados da mortalidade diária foram submetidos à análise estatística pelo programa Spearman-Karber (US EPA, Washington, DC, EUA), e a $\mathrm{CL}_{50}$ determinada foi de $10^{8} \mathrm{UFC} \mathrm{mL}^{-1}$.

Para a confecção da vacina, o microrganismo foi semeado em $500 \mathrm{~mL}$ de caldo "brain heart infusion" (BHI) (Voigt Global Distribution Inc., Lawrence, $\mathrm{KS}$, EUA). Após cinco dias de incubação a $29^{\circ} \mathrm{C}$, em aerofilia, o meio foi centrifugado a $300 \mathrm{~g}$, a $4^{\circ} \mathrm{C}$, durante 20 min. O sobrenadante foi desprezado e a massa bacteriana foi ressuspendida em $500 \mathrm{~mL}$ de tampão fosfato salino (PBS) e novamente centrifugada. Essa operação foi repetida por três vezes.

A massa bacteriana foi diluída em $100 \mathrm{~mL}$ de PBS de modo a conter $10^{8} \mathrm{UFC} \mathrm{mL}^{-1}$, correspondente ao grau oito da escala de MacFarland. A solução foi incubada em banho-maria, por $30 \mathrm{~min}$, a $40^{\circ} \mathrm{C}$, para inativação confirmada por semeadura em meio BHI, incubado a $29^{\circ} \mathrm{C}$, por sete dias. Na ausência de crescimento bacteriano, o adjuvante incompleto de Freund, na diluição $1: 1$, foi incorporado à vacina e emulsionado em misturador elétrico. Com a solução mantida em gelo, realizou-se o teste de emulação e a preparação das doses. Alíquotas de $0,5 \mathrm{~mL}$ foram transferidas para seringas de $1 \mathrm{~mL}$ e mantidas em gelo até o momento da vacinação.

A vacinação (G1 e G4) foi realizada 60 dias após o início da alimentação dos peixes. Para isso, $0,5 \mathrm{~mL}$ da solução oleosa de $S$. agalactiae, contendo $10^{8}$ UFC, foi inoculado por via intracelomática (i.c.). Os peixes não vacinados (G2 e G3) receberam $0,5 \mathrm{~mL}$ de adjuvante incompleto de Freund, i.c.. Após 15 dias, todos os peixes foram desafiados com cepa homóloga de $S$. agalactiae, por inoculação i.c. de $10^{8}$ UFC, veiculada em $0,5 \mathrm{~mL}$ de solução salina $(0,85 \%)$ (Comitê de ética, no 03868/07).

Os peixes que vieram a óbito (dezembro de 2007 a março de 2008) foram encaminhados para reisolamento de $S$. agalactiae. Para tanto, foram coletadas assepticamente amostras de rim e encéfalo, que foram semeadas em placas contendo ágar Columbia (Voigt Global Distribution Inc., Lawrence, KS, EUA), suplementadas com $1 \%$ de extrato de levedura e $5 \%$ de sangue de ovino desfibrinado, e incubadas a $29^{\circ} \mathrm{C}$, em aerofilia, por cinco dias. As colônias suspeitas foram identificadas (Salvador et al., 2005).

As biometrias foram realizadas no início e no final do período de alimentação (77 dias), por meio da utilização de balança digital e ictiômetro para cálculos de: ganho de peso, GP = (peso final - peso inicial); taxa de crescimento específico, TCE $=[100 \times(\ln$ peso final - In peso inicial) / dias de experimento)]; e fator de condição, $\left.\mathrm{K}=\left\{[\text { peso/(comprimento })^{3}\right] \times 100\right\}$ (Bolger \& Connolly, 1989).

Para a determinação das variáveis hematológicas, nos tempos de 6, 24 e 48 HPD, os peixes foram anestesiados por banho em solução de benzocaína (1:20.000), diluída em álcool $98^{\circ}\left(0,1 \mathrm{~g} \mathrm{~mL}^{-1}\right)$ (Belo et al., 2012), e o sangue ( $2 \mathrm{~mL}$ em EDTA $10 \%$ ) foi coletado da veia caudal. Uma alíquota do sangue foi destinada à contagem de eritrócitos em contador automático de células sanguíneas, modelo CC510 (Celm Cia. Equipadora de Laboratórios Modernos, Barueri, SP), e o percentual do hematócrito foi determinado segundo Goldenfarb et al. (1971). De posse dos resultados, foram calculados os seguintes índices hematimétricos: volume corpuscular médio e concentração de hemoglobina corpuscular média. Os leucócitos totais foram contados em câmara de Neubauer, de acordo com método descrito por Tavares-Dias et al. (1999), e as colorações foram feitas conforme Tavares-Dias \& Moraes (2007).

Os dados obtidos foram avaliados por meio do procedimento GLM do SAS, versão 2001 (SAS Institute, Cary, NC, EUA), tendo-se considerado os efeitos de levedura, vacina, tempo e suas interações. 
Comparações múltiplas de médias foram realizadas pelo teste de Tukey-Kramer, a 5\% de probabilidade.

\section{Resultados e Discussão}

As maiores médias de ganho de peso (GP) e taxa de crescimento especifico (TCE) observadas nos peixes alimentados com ração suplementada (Tabela 2) podem ser parcialmente justificadas pelo conteúdo de $\beta$-glucanos e $\alpha$-mananos, carboidratos responsáveis por aumentar o desempenho produtivo. De modo geral, os processos fisiopatológicos dos teleósteos apresentam diferenças em seus padrões (Swain et al., 2008). Entretanto, o emprego de levedura e seus derivados melhora a produtividade de diversas espécies de peixes, em razão da melhora na eficiência alimentar e do incremento dos mecanismos de defesa inespecíficos (Rodriguez et al., 2003; Abdel-Tawwab et al., 2008; Reque et al., 2010).

$\mathrm{O}$ aumento das taxas de hematócrito e hemoglobina nos peixes alimentados com dietas suplementadas e vacinados reforça a inferência de que o polissacarídeo da parede celular de levedura, juntamente com a vacina, contribui para o equilíbrio orgânico da tilápia-do-nilo,

Tabela 2. Parâmetros zootécnicos de tilápias-do-nilo (Oreochromis niloticus) submetidas à suplementação dietética com $0,3 \%$ de parede celular de levedura (PCL) de Saccharomyces cerevisiae e vacinadas contra Streptococcus agalactiae $^{(1)}$.

\begin{tabular}{lcccc}
\hline Tratamento & $\begin{array}{c}\text { Ganho de } \\
\text { peso }(\mathrm{g})\end{array}$ & $\begin{array}{c}\text { Comprimento } \\
\text { final }(\mathrm{cm})\end{array}$ & $\begin{array}{c}\text { Fator de } \\
\text { condição }\end{array}$ & TCE ${ }^{(2)}$ \\
\hline $0,3 \%$ de PCL & $142,83 \mathrm{a}$ & 26,71 & 0,74 & $190,44 \mathrm{a}$ \\
$0,0 \%$ de PCL & $129,09 \mathrm{~b}$ & 26,05 & 0,73 & $172,12 \mathrm{~b}$ \\
\hline Com vacina & 137,70 & 26,17 & 0,76 & 183,59 \\
Sem vacina & 136,99 & 26,70 & 0,71 & 182,66 \\
\hline 6 horas & 139,57 & 26,82 & 0,72 & 186,10 \\
24 horas & 135,20 & 25,67 & 0,79 & 180,27 \\
48 horas & 137,23 & 26,82 & 0,71 & 182,98 \\
\hline & & Valores do teste F & \\
Levedura (L) & $21,0472 *$ & 0,6926 & 0,0104 & $21,0472 *$ \\
Vacina (V) & 0,0573 & 0,4571 & 0,0126 & 0,0573 \\
Tempo (T) & 0,7280 & 0,9633 & 0,0031 & 0,7280 \\
L x V & 0,0534 & 1,7361 & 0,0786 & 0,0534 \\
Lx T & 0,3505 & 1,0847 & 0,0188 & 0,3505 \\
V x T & 0,9065 & 1,3277 & 0,0036 & 0,9065 \\
L x V x T & 0,3060 & 2,9736 & 0,0277 & 0,3060 \\
\hline CV $(\%)$ & 8,94 & 12,30 & 20,20 & 8,94
\end{tabular}

(1)Médias seguidas de letras iguais, nas colunas, não diferem pelo teste de Tukey-Kramer, a 5\% de probabilidade. *Significativo pelo teste F, a 5\% de probabilidade. ${ }^{(2)} \mathrm{TCE}$, taxa de crescimento especifico. por meio de provável estimulação eritropoiética (Tabela 3). Martins et al. (2001) relataram redução significativa no valor do hematócrito em tilápias-do-nilo submetidas a agentes estressores, como captura e manejo. No presente trabalho, o estresse, representado pelo desafio com $S$. agalactiae, provocou redução significativa no hematócrito de peixes alimentados com ração controle e não vacinados (Tabela 3 ). Isso sugere que o fornecimento de dietas suplementadas com levedura ou a vacinação seja capaz de minimizar, em parte, os efeitos nocivos do estresse em relação ao hematócrito.

O maior volume corpuscular médio (VCM) e o menor hematócrito observados nos peixes alimentados com a ração controle e não vacinados corroboram a constatação de que quanto maior o número de eritrócitos, maior a taxa de hemoglobina e menor o VCM (Tavares-dias \& Moraes, 2004). O valor do VCM ao longo das coletas dos peixes alimentados com a ração controle ou dos não vacinados aumentou significativamente, embora o hematócrito não tenha apresentado diferença significativa entre os grupos. Nos peixes submetidos a agentes incapazes de

Tabela 3. Parâmetros hematológicos de tilápias-do-nilo (Oreochromis niloticus) submetidas à suplementação dietética com $0,3 \%$ de parede celular de levedura (PCL) de Saccharomyces cerevisiae e vacinadas contra Streptococcus agalactiae $^{(1)}$.

\begin{tabular}{lccccc}
\hline Tratamento & $\begin{array}{c}\text { Eritrócito } \\
\left(10^{6} \mu \mathrm{L}^{-1}\right)\end{array}$ & $\begin{array}{c}\text { Hematócrito } \\
(\%)\end{array}$ & $\begin{array}{c}\text { Hemoglobina } \\
\left(\mathrm{g} \mathrm{dL}^{-1}\right)\end{array}$ & $\begin{array}{c}\mathrm{VCM}^{(2)} \\
(\mathrm{fL})\end{array}$ & $\begin{array}{c}\mathrm{CHC}^{(3)} \\
(\%)\end{array}$ \\
\hline $0,3 \%$ de PCL & $2,04 \mathrm{a}$ & $36.80 \mathrm{a}$ & $11,92 \mathrm{a}$ & $162,95 \mathrm{a}$ & 32,76 \\
0,0\% de PCL & $1,96 \mathrm{~b}$ & $35,08 \mathrm{~b}$ & $11,31 \mathrm{~b}$ & $169,91 \mathrm{~b}$ & 33,54 \\
\hline Com vacina & $2,04 \mathrm{a}$ & $37,56 \mathrm{a}$ & $12,01 \mathrm{a}$ & $168,57 \mathrm{a}$ & 32,62 \\
Sem vacina & $1,98 \mathrm{~b}$ & $34,75 \mathrm{~b}$ & $11,36 \mathrm{~b}$ & $163,08 \mathrm{~b}$ & 33,50 \\
\hline 6 horas & 2,04 & $34,47 \mathrm{a}$ & $11,44 \mathrm{a}$ & $173,29 \mathrm{a}$ & $34,41 \mathrm{a}$ \\
24 horas & 2,00 & $36,00 \mathrm{~b}$ & $11,68 \mathrm{ab}$ & $149,22 \mathrm{~b}$ & $32,76 \mathrm{~b}$ \\
48 horas & 1,99 & $37,80 \mathrm{c}$ & $11,90 \mathrm{~b}$ & $174,32 \mathrm{a}$ & $32,09 \mathrm{c}$ \\
\hline \multicolumn{5}{c}{ Valores do teste F } \\
Levedura (L) & $5,65 *$ & $8,71 *$ & $17,50 *$ & $23,16^{*}$ & 1,19 \\
Vacina (V) & $4,52^{*}$ & $24,46^{*}$ & $20,45^{*}$ & $14,79 *$ & 1,59 \\
Tempo (T) & 0,95 & $11,49 *$ & $3,44 *$ & $132,93 *$ & $3,94 *$ \\
L x V & $4,32^{*}$ & $223,89^{*}$ & 1,25 & $54,40^{*}$ & 11,69 \\
L x T & $6,94^{*}$ & $10,92^{*}$ & 2,15 & $62,11 *$ & 1,93 \\
V x T & $5,09 *$ & $6,83 *$ & $17,50^{*}$ & $73,06^{*}$ & 2,07 \\
\hline CV (\%) & 6,28 & 6,60 & 5,15 & 3,58 & 8,8 \\
\hline
\end{tabular}

${ }^{(1)}$ Médias seguidas de letras iguais, nas colunas, não diferem pelo teste de Tukey-Kramer, a 5\% de probabilidade. *Significativo pelo teste F, a 5\% de probabilidade. ${ }^{(2)} \mathrm{VCM}$, volume corpuscular médio. ${ }^{(3)} \mathrm{CHC}$, concentração de hemoglobina corpuscular. 
estimular o aumento da população eritrocitária, a presença de eritrócitos macrocíticos é um mecanismo de compensação para aumentar a eficiência do transporte de oxigênio e manter a demanda energética (Martins et al., 2004).

Em teleósteos, a composição sanguínea é dependente de fatores fisiológicos e ecológicos, tais como sexo, estágio de desenvolvimento gonadal, estresse, infecções e desequilíbrios ambientais (Tavares-Dias \& Moraes, 2004). Neste contexto, o número de leucócitos varia entre famílias, gêneros e espécies, e de acordo com o ambiente (Tavares-dias \& Moraes, 2004).

A análise das variáveis hematológicas mostrou que os peixes alimentados com dietas suplementadas ou vacinados apresentaram número médio de leucócitos e trombócitos superiores aos dos peixes alimentados com a ração controle ou não vacinados, respectivamente (Tabela 4). Quando ocorre a invasão de microrganismos, o sistema imune inicia a ativação e a proliferação de leucócitos e trombócitos (Kollner et al., 2002), os quais estão envolvidos na defesa do organismo (Bozzo et al., 2007; Claudiano et al., 2013).

O maior aumento do número de leucócitos totais foi observado nos peixes alimentados com dietas suplementadas e vacinados, o que suporta a hipótese

Tabela 4. Médias de leucócitos totais e trombócitos de tilápias-do-nilo (Oreochromis niloticus) submetidas à suplementação dietética com $0,3 \%$ de parede celular de levedura (PCL) de Saccharomyces cerevisiae e vacinadas contra Streptococcus agalactiae $e^{(1)}$.

\begin{tabular}{lcc}
\hline Tratamento & Leucócitos totais $\left(10^{6} \mu \mathrm{L}^{-1}\right)$ & Trombócitos $\left(10^{6} \mu \mathrm{L}^{-1}\right)$ \\
\hline $0,3 \%$ de PCL & $0,21 \mathrm{a}$ & $0,028 \mathrm{a}$ \\
$0,0 \%$ de PCL & $0,13 \mathrm{~b}$ & $0,026 \mathrm{~b}$ \\
\hline Com vacina & $0,20 \mathrm{a}$ & $0,027 \mathrm{a}$ \\
Sem vacina & $0,15 \mathrm{~b}$ & $0,025 \mathrm{~b}$ \\
\hline 6 horas & $0,14 \mathrm{a}$ & 0,027 \\
24 horas & $0,21 \mathrm{~b}$ & 0,027 \\
48 horas & $0,18 \mathrm{~b}$ & 0,027 \\
\hline & & \\
Levedura (L) & $99,29 *$ & $16,50 *$ \\
Vacina (V) & $40,58^{*}$ & $7,49 *$ \\
Tempo (T) & $35,05^{*}$ & 0,88 \\
Lx V & $72,31 *$ & $-0,75$ \\
Lx T & $32,51^{*}$ & $10,13 *$ \\
V x T & $18,08^{*}$ & 2,92 \\
\hline CV $(\%)$ & 16,27 & 6,43
\end{tabular}

${ }^{(1)}$ Médias seguidas de letras iguais, nas colunas, não diferem pelo teste de Tukey-Kramer, a 5\% de probabilidade. *Significativo pelo teste F, a 5\% de probabilidade. de que a parede celular da levedura favorece a resposta inflamatória e melhora as ações de defesa do organismo (Reque et al., 2010). Os monócitos e os macrófagos são as células primárias responsáveis pela captura, pelo processamento e pela apresentação de antígenos aos linfócitos, o que resulta na sua proliferação e ativação (Misra et al., 2006). O aumento no número de linfócitos observados a partir da segunda coleta (Tabela 5) pode ter sido consequência do período requerido para este processo. A demanda energética durante o processo de ativação linfocitária é decisiva na resposta imune dos peixes (Bozzo et al., 2007). No presente trabalho, os peixes alimentados com a ração controle não apresentaram alterações nestes valores (Tabela 5). Assim, o efeito da levedura contida na dieta sugere que ela seja capaz de incrementar o nível nutricional e, portanto, melhorar o patamar de saúde dos peixes.

Os neutrófilos são células de defesa sensíveis à desnutrição proteica e energética, e seus valores podem variar de acordo com a composição da dieta do peixe (Flajnik \& Du Pasquier, 2004). Os resultados obtidos confirmaram essa observação, pois os maiores valores de neutrófilos foram constatados nos peixes alimentados com dietas suplementadas (Tabela 5).

Tabela 5. Número total de linfócitos, neutrófilos e monócitos de tilápias-do-nilo (Oreochromis niloticus) submetidas à suplementação dietética com $0,3 \%$ de parede celular de levedura (PCL) de Saccharomyces cerevisiae e vacinadas contra Streptococcus agalactiae ${ }^{(1)}$.

\begin{tabular}{lccc}
\hline Tratamento & $\begin{array}{c}\text { Linfócitos } \\
\left(10^{4} \mu \mathrm{L}^{-1}\right)\end{array}$ & $\begin{array}{c}\text { Neutrófilos } \\
\left(10^{4} \mu \mathrm{L}^{-1}\right)\end{array}$ & $\begin{array}{c}\text { Monócitos } \\
\left(10^{4} \mu \mathrm{L}^{-1}\right)\end{array}$ \\
\hline $0,3 \%$ de PCL & $14,39 \mathrm{a}$ & $11,05 \mathrm{a}$ & $1,19 \mathrm{~b}$ \\
$0,0 \%$ de PCL & $8,00 \mathrm{~b}$ & $7,27 \mathrm{~b}$ & $2,60 \mathrm{a}$ \\
\hline Com vacina & $12,85 \mathrm{a}$ & $10,75 \mathrm{a}$ & $2,02 \mathrm{a}$ \\
Sem vacina & $10,87 \mathrm{~b}$ & $8,39 \mathrm{~b}$ & $1,51 \mathrm{~b}$ \\
\hline 6 horas & $7,93 \mathrm{c}$ & $7,62 \mathrm{c}$ & $1,99 \mathrm{a}$ \\
24 horas & $14,60 \mathrm{a}$ & $11,45 \mathrm{a}$ & $1,62 \mathrm{c}$ \\
48 horas & $12,93 \mathrm{~b}$ & $9,54 \mathrm{~b}$ & $1,66 \mathrm{~b}$ \\
\hline & & Valores do teste F & \\
Levedura (L) & $142,77^{*}$ & $99,29^{*}$ & $111,71^{*}$ \\
Vacina (V) & $14,23^{*}$ & $40,58^{*}$ & $15,47^{*}$ \\
Tempo (T) & $57,82^{*}$ & $35,05^{*}$ & 3,07 \\
L x V & $54,02^{*}$ & $72,31^{*}$ & $373,27^{*}$ \\
L x T & $58,35^{*}$ & $32,51^{*}$ & $9,86^{*}$ \\
V x T & $10,53^{*}$ & $18,08^{*}$ & $12,37^{*}$ \\
\hline CV $(\%)$ & 8,75 & 21,48 & 22,01 \\
\hline
\end{tabular}

${ }^{(1)}$ Médias seguidas de letras iguais, nas colunas, não diferem pelo teste de Tukey-Kramer, a $5 \%$ de probabilidade. *Significativo pelo teste $\mathrm{F}$, a $5 \%$ de probabilidade. 
Os monócitos, além de produzirem citocinas, são células primárias na apresentação de antígenos em teleósteos, como a tilápia-do-nilo, e têm funções de célula de defesa em trânsito no sangue periférico (Dalmo \& Bogwald, 2008). Verificou-se que o maior número de monócitos ocorreu nos peixes submetidos exclusivamente à vacinação (Tabela 5). Esse resultado pode estar relacionado à ativação de linfócitos determinada pela vacinação e pela consequente produção de citocinas, como o GM-CSF (fator estimulatório de colônias de granulócitos e monócitos), que resultaria no aumento do número de monócitos no sangue (Roitt et al., 1998).

A suplementação com levedura favoreceu patamares mais elevados de equilíbrio orgânico, assim como respostas de defesa não específicas. Observou-se, também, que a vacinação contribuiu para a estimulação da resposta imune específica.

\section{Conclusões}

1. Maiores taxas de ganho de peso e crescimento específico são obtidas em tilápias-do-nilo (Oreochromis niloticus) submetidas à suplementação da dieta com $0,3 \%$ de parede celular de levedura.

2. A interação entre a suplementação da dieta com parede celular de levedura e a vacinação dos peixes contra Streptococcus agalactiae contribui para o equilíbrio orgânico e as ações de defesa do organismo, por meio de maiores taxas de hematócrito, hemoglobina e leucócitos.

\section{Referências}

ABDEL-TAWWAB, M.; ABDEL-RAHMAN, A.M.; ISMAEL, N.E.M. Evaluation of commercial live bakers' yeast, Saccharomyces cerevisiae as a growth and immunity promoter for Fry Nile tilapia, Oreochromis niloticus (L.) challenged in situ with Aeromonas hydrophila. Aquaculture, v.280, p.185-189, 2008. DOI: 10.1016/j. aquaculture.2008.03.055.

BACCARIN, A.E.; PEZZATO, L.E. Efeito da utilização da levedura desidratada de álcool em dietas para tilápia-do-nilo. Pesquisa Agropecuária Brasileira, v.36, p.549-556, 2001. DOI: 10.1590/S0100-204X2001000300021.

BELO, M.A.A.; SCHALCH, S.; MORAES, F.R.; SOARES, V.; OTOBONI, A.; MORAES, J. Effect of dietary supplementation with vitamin $\mathrm{E}$ and stocking density on macrophage recruitment and giant cell formation in the teleost fish, Piaractus mesopotamicus. Journal of Comparative Pathology, v.133, p.146-154, 2005. DOI: $10.1016 /$ j.jcpa.2005.04.004.
BELO, M.A. de A.; MORAES, J.R.E. de; SOARES, V.E.; MARTINS, M.L.; BRUM, C.D.; MORAES, F.R. Vitamin C and endogenous cortisol in foreign-body inflammatory response in pacus. Pesquisa Agropecuária Brasileira, v.47, p.1015-1021, 2012. DOI: $10.1590 / \mathrm{S} 0100-204 X 2012000700019$.

BOLGER, T.; CONNOLLY, P.L. The selection of suitable indexes for the measurement and analysis of fish condition. Journal of Fish Biology, v.34, p.171-182, 1989. DOI: 10.1111/j.1095-8649.1989. tb03300.x.

BOYD, C.E. Water quality in ponds for aquaculture. Alabama: Auburn University, 1990. 482p.

BOZZO, F.R.; MORAES, J.R.E. de; MORAES, F.R. de; PEREIRA, G.; TAVARES-DIAS, M.; ONAKA, E.M. Kinetics of cellular component in inflammatory response induced by different stimuli in the swim bladder of pacu Piaractus mesopotamicus Holmberg, 1887 (Characidae). Journal of the World Aquaculture Society, v.38, p.302-308, 2007. DOI: 10.1111/j.1749-7345.2007.00100.x.

CLAUDIANO, G. da S.; PETRILLO, T.R.; MANRIQUE, W.G.; CASTRO, M.P.; LOUREIRO, B.A.; MARCUSSO, P.F.; BELO, M.A.A.; MORAES, J.R.E. de; MOREAS, F.R. Acute aerocystitis in Piaractus mesopotamicus: participation of eicosanoids and pro-inflammatory cytokines. Fish and Shellfish Immunology, v.34, p.1057-1062, 2013. DOI: 10.1016/j.fsi.2013.01.006.

DALMO, R.A.; BOGWALD, J. Beta-glucans as conductors of immune symphonies. Fish and Shellfish Immunology, v.25, p.384-396, 2008. DOI: 10.1016/j.fsi.2008.04.008.

EVANS, J.J.; KLESIUS, P.H.; GILBERT, P.M.; SHOEMAKER, C.A.; Al SARAWI, M.A.; LANDSBERG, J.; DUREMDEZ, R.; AL MARZOUK, A.; AL ZENKI, S. Characterization of b-haemolytic group B Streptococcus agalactiae in cultured seabream, Sparus auratus L., and wild mullet, Liza klunzingeri (Day), in Kuwait. Journal of Fish Diseases, v.25, p.505-513, 2002. DOI: 10.1046/j. 1365-2761.2002.00392.x.

EVANS, J.J.; KLESIUS, P.H.; SHOEMAKER, C.A. Efficacy of Streptococcus agalactiae (group B) vaccine in tilapia (Oreochromis niloticus) by intraperitoneal and bath immersion administration. Vaccine, v.22, p.3769-3773, 2004. DOI: 10.1016/j. vaccine.2004.03.012.

FLAJNIK, M.F.; DU PASQUIER, L. Evolution of innate and adaptive immunity: can we draw a line? Trends in Immunology, v.25, p.640-644, 2004. DOI: 10.1016/j.it.2004.10.001.

GOLDENFARB, P.B.; BOWYER, F.P.; HALL, E.; BROSIOUS, E. Reproducibility in the hematology laboratory: the microhematocrit determination. American Journal of Clinical Pathology, v.56, p.35-39, 1971.

KOLLNER, B.; WASSERRAB, B.; KOTTERBA, G.; FISHER, U. Evaluation of immune functions of rainbow trout (Oncorhynchus mykiss) - how can environmental influences be detected? Toxicology Letters, v.131, p.83-95, 2002. DOI: 10.1016/ S0378-4274(02)00044-9.

LEVY, S.B.; MARSHALL, B. Antibacterial resistance worldwide: causes, challenges and responses. Nature Medicine, v.10, p.122-129, 2004. DOI: 10.1038/nm1145.

Pesq. agropec. bras., Brasília, v.48, n.8, p.892-898, ago. 2013 DOI: $10.1590 / \mathrm{S} 0100-204 \mathrm{X} 2013000800012$ 
MARTINS, M.L.; ONAKA, E.M.; TAVARES-DIAS, M.; BOZZO, F.R.; MALHEIROS, E.B. Características hematológicas do híbrido tambacu, seis e 24 horas após a injeção de substâncias irritantes na bexiga natatória. Revista de Ictiologia, v.9, p.25-31, 2001.

MARTINS, M.L.; PILARSKY, F.; ONAKA, E.M.; NOMURA, D.T.; FENERICK JUNIOR, J.; RIBEIRO, K.; MYIAZAKI, D.M.Y.; DE CASTRO, M.P.; MALHEIROS, E.B. Hematologia e resposta inflamatória aguda em Oreochromis niloticus (Osteichthyes: Cichlidae) submetida aos estímulos único e consecutivo de estresse de captura. Boletim do Instituto de Pesca, v.30, p.71-80, 2004

MISRA, C.K.; DAS, B.K.; MUKHERJEE, S.C.; PATTNAIK, P. Effect of long term administration of dietary $\beta$-glucan on immunity, growth and survival of Labeo rohita fingerlings. Aquaculture, v.255, p.82-94, 2006. DOI: 10.1016/j.aquaculture.2005.12.009.

MORAES, F.R.; MORAES, J.R.E. Nutracêuticos na inflamação e cicatrização de peixes de interesse zootécnico. In: TAVARES-DIAS, M. (Ed.). Manejo e sanidade de peixes em cultivo. Macapá: Embrapa Amapá, 2009. p.625-723.

REQUE, V.R.; MORAES, J.R.E. de; BELO, M.A.A.; MORAES, F.R. Inflammation induced by Aeromonas hydrophila in Nile tilapia fed diets supplemented with Saccharomyces cerevisiae. Aquaculture, v.300, p.37-42, 2010. DOI: 10.1016/j. aquaculture.2009.12.014.

RODRIGUEZ, A.; CUESTA, A.; ORTUNO, J.; ESTEBAN, M.A.; MESEGUER, J. Immunostimulant properties of a cell wall-modified whole Saccharomyces cerevisiae strain administered by diet to seabream (Sparus aurata L.). Veterinary Immunology and Immunopathology, v.96, p.183-192, 2003. DOI: 10.1016/j. vetimm.2003.07.001.

ROITT, I.; BROSTOFF, J.; MALI, D. Immunology. London: Mosby, 1998. 423p.
SALVADOR, R.; MULLER, E.E.; FREITAS, J.C. de; LEONHARDT, J.H.; PRETTO-GIORDANO, L.G.; DIAS, J.A. Isolation and characterization of Streptococcus spp. group B from Nile tilapias (Oreochromis niloticus) reared in hapas nets and earth nurseries in the northern region of Parana State, Brazil. Ciência Rural, v.35, p.1374-1378, 2005. DOI: 10.1590/ S0103-84782005000600023.

SALVADOR, R.; TOAZZA, C.S.; MORAES, J.R.E. de; MORAES, F.R. Inflammatory responses of Nile tilapia Oreochromis niloticus to Streptococcus agalactiae: effects of vaccination and yeast diet supplement. Diseases of Aquatic Organisms, v.98, p.235-241, 2012. DOI: $10.3354 /$ dao02438.

SIPAÚBA-TAVARES, L.E.; MORENO, S.Q. Variação dos parâmetros limnológicos em um viveiro de piscicultura nos períodos de seca e chuva. Revista Unimar, v.16, p.229-242, 1994.

SWAIN, P.; NAYAK, S.K.; NANDA, P.K.; DASH, S. Biological effects of bacterial lipopolysaccharide (endotoxin) in fish: a review. Fish and Shellfish Immunology, v.25, p.191-201, 2008. DOI: 10.1016/j.fsi.2008.04.009.

TAVARES DIAS, M.; MORAES, F.R. de. Hematologia de peixes teleósteos. Ribeirão Preto: FMRP, 2004. 144p.

TAVARES-DIAS, M.; MORAES, F.R. Leukocyte and thrombocyte reference values for channel catfish (Ictalurus punctatus Raf), with an assessment of morphologic, cytochemical, and ultrastructural features. Veterinary Clinical Pathology, v.36, p.49-54, 2007. DOI: 10.1111/j.1939-165X.2007.tb00181.x.

TAVARES-DIAS, M.; SANDRIM, E.F.S.; CAMPOS-FILHO, E. de. Características hematológicas do tambaqui Colossoma macropomum Cuvier (Osteichthyes, Characidae) em sistema de monocultivo intensivo. II. Leucócitos. Revista Brasileira de Zoologia, v.16, p.175-184,1999. DOI: 10.1590/ S0101-81751999000100012.

Recebido em 28 de julho de 2011 e aprovado em 26 de julho de 2013 